OPEN ACCESS

Edited by:

Federico Giove,

Centro Fermi, Italy

Reviewed by:

Fei Geng,

McMaster University, Canada

Silvia Capuani,

Consiglio Nazionale Delle Ricerche

(CNR), Italy

*Correspondence:

Ioannis Gkiatas

john.gkiatas@gmail.com

Specialty section:

This article was submitted to

Biomedical Physics,

a section of the journal

Frontiers in Physics

Received: 27 April 2017

Accepted: 07 September 2017

Published: 21 September 2017

Citation:

Gkiatas I, Papadopoulos D, Pakos EE,

Kostas-Agnantis I, Gelalis I, Vekris M and Korompilias A (2017) The

Multifactorial Role of Peripheral

Nervous System in Bone Growth.

Front. Phys. 5:44

doi: 10.3389/fphy.2017.00044

\section{The Multifactorial Role of Peripheral Nervous System in Bone Growth}

\author{
Ioannis Gkiatas*, Dimitrios Papadopoulos, Emilios E. Pakos, loannis Kostas-Agnantis, \\ Ioannis Gelalis, Marios Vekris and Anastasios Korompilias
}

Orthopaedic Department, University Hospital of loannina, loannina, Greece

Bone alters its metabolic and anabolic activities in response to the variety of systemic and local factors such as hormones and growth factors. Classical observations describing abundance of the nerve fibers in bone also predict a paradigm that the nervous system influences bone metabolism and anabolism. Since 1916 several investigators tried to analyze the effect of peripheral nervous system in bone growth and most of them advocated for the positive effect of innervation in the bones of growing organisms. Moreover, neuronal tissue controls bone formation and remodeling. The purpose of this mini-review is to present the most recent data concerning the influence of innervation on bone growth, the current understanding of the skeletal innervation and their proposed physiological effects on bone metabolism as well as the implication of denervation in human skeletal biology in the developing organism since the peripheral neural trauma as well as peripheral neuropathies are common and they have impact on the growing skeleton.

Keywords: bone growth, calcitonin gene-related peptide, vasoactive intestinal peptide, substance p, denervation, muscles

\section{INTRODUCTION}

Bone growth consists a multifactorial procedure. It has a very complicated regulation, which is made by numerous and complex interactions not only genetic, such as hormones, but also environmental factors like mechanical load. Starting from the genetic factors, growth factor, insulin-like growth factor 1 (IGF-1), triiodothyronine, thyroxine, androgens, Indian hedgehog, fibroblast growth factors, bone morphogenetic proteins (BMPs), vascular endothelial growth factors (VEGF) are some of them which affect positively the bone growth [1]. On the other hand, glucocorticoids, estrogens and parathyroid hormone-related peptide (PtHrp) have negative effect on the development of the bones [2].

Concerning the environmental factors, the mechanical forces influence bone formation as well as adaptation [3]. The proposed graph of Frost in 1997 [4] is generally accepted and it depicts the idea that compression up to a certain level, can promote bone growth, whereas after a certain level the bone development is inhibited.

One of the most important coefficients for the mechanical regulation of bone growth is the innervation, due to the fact that it imparts movement to the muscles, which provide the compression or tension to the bones. The purpose of this mini-review is to collect, analyze and present all the current concepts as far as it concerns the effect of the peripheral nervous system on bone growth in order to identify developmental diseases and fracture risk after peripheral nerve injury. 


\section{ANATOMY AND PHYSIOLOGY OF BONE INNERVATION}

\section{Anatomy}

The innervation of the bone follows the Hilton rule. This means that the nervous supply of the muscles and skin is continuous with the long bones and joints. The main arteries, which are responsible for the feeding of the bone in different areas, run along with the large nerve bundles. The medullary space is innervated by the biggest nerve entering into the diaphysis of the bone through the nutrient foramen. Other nerves manage to get into the bone via the articular surfaces either on the proximal or the distal side of the bone [5]. More explicitly, the nerves are distributed in bone in a way which has been extensively studied and described, emphasizing on the nerves with neuropeptidecontaining fibers [6-8]. Most of the peripheral nerves in bones are located with the blood vessels. In several studies sensory as well as autonomic fibers were found in different areas of the bone including the vessels located in the periosteum, Volkmann's canals, bone marrow, osteochondral junction of the growth plate and the attachment of the synovial membrane [7-10]. On the other hand, in other studies, it has been shown that an intensive network of sensory and sympathetic nerve fibers within the skeleton are mainly located within the trabecular and less in cortical bone, bone marrow, and epiphyseal growth plate [8, 9, $11,12]$. Neuropeptides are present not only in normal conditions, but they have also been implicated in regional disease processes such as bone growth, repair and remodeling [12-16].

There is a category of secreted and membrane proteins called semaphorins, which mediate axonal guidance, regulate the innervation of bone, specifically by Sema3A expression in bone cells [17]. This is a kind of mechanism according to which the growing bones are able to control their own innervation [5].

\section{Physiology}

The bone can be described as a living tissue which has the ability of continuous remodeling. It generally consists of a small number of nerve fibers. Despite this fact, these fibers may act as regulators which are able to deliver time- and site-specific stimuli according to demand [15]. The role of the nerves, which are distributed to bones, have a double role: the first one is the regulation of bony mechanical forces and their second role is to act as a source trophic factors which are crucial not only for the functionality of the bone but also for its structure [16]. The molecules which are related to nerves seem to have influence on the metabolism of normal bone. In general, it is concluded that after a fracture with an altered nerve supply, the sensory nerve supply does not recognize the abnormal movement of the fracture and, with unstable fixation, nerves may mediate signals that lead to altered bone healing.

\section{NEUROPEPTIDES INVOLVED IN BONE METABOLISM}

There are numerous neuropeptides which have been found to take part in bone metabolism [18]. Nevertheless, there are three of them, that seem to be the most important and have been investigated extensively.

\section{Calcitonin-Gene Related Peptide (CGRP)}

It consists of 37 amino acids. It is produced by tissue specific alternative processing of the primary RNA transcripts of the calcitonin gene. In experimental models in rat femurs [12], it was found that during the metabolism of the bone there are numerous CGRP-positive nerve fibers in the metaphysis during 10 days after birth when the animals started to stand on their feet. Moreover, CGRP-positive nerve fibers were more plenteous around the epiphysis compared to the metaphysis, and they were located along the epiphyseal trabeculae, facing the growth plate. In another experimental study Schwab et al. [19] demonstrated that CGRP-immunoreactive nerve fibers were present in the outer layer of articular cartilage and they were contacted to chondrocytes in the knee joints of both infant and mature rats. In general, it seems that a direct action of CGRP regulates the cellular activities of osteoblast. More explicitly, the main role of CGRP is the enhancement of cyclic adenosine monophosphate (cAMP) production by the primary human osteoblasts. On the other hand, it has been shown that CGRP seems to inhibit osteoclastic resorption in vitro, such as calcitonin, although the inhibitory activity of CGRP is approximately 1,000-fold less potent at equivalent doses [20]. Moreover, the close contacts of nerve fibers containing CGRP with osteoclasts seem to regulate several osteoclastic activities.

\section{Vasoactive Intestinal Peptide (VIP)}

This is an almost always present peptide consisting of 28 amino acids. It is a cleavage product of pre-pro-VIP, which is originally derived from the intestine of swine. It has been proved to be an efficacious regulator that activates adenylate cyclase in multiple organ systems [15]. The bone is influenced by VIP through receptors paired with two types of proteins belonging to the $\mathrm{G}$ family:7,27,62 Gs protein and Gplc protein $[21,22]$. The VIP receptors connected to Gs protein enable bone resorption through a cAMP-dependent mechanism. Osteoblastic osteosarcoma cells have proved to respond to tiny concentrations of VIP with increases in cAMP, and whole mouse skullcaps are resorbed affected by the VIP [23].

\section{Substance P (SP)}

It is another neuropeptide which is found in the nerve fibers. Despite the fact that the fibers containing SP are fewer compared to those containing CGRP, they innervate the medullary tissues of the bone as well as the periosteum [24]. The role of SP is the stimulation of cAMP production by osteoblastic cells [25]. Nevertheless, there is evidence that SP also contributes in the stimulation of the osteoclasts' activities such as the expression of neurokinin-1 receptor through which SP causes signal transduction [26]. SP is also responsible for the stimulation of the formation of the resorption pit by cultured osteoclasts at about $170 \%$, which can be revered by addition of an SP antagonist, spantide [27]. 
In general, CGRP, VIP and SP take part in the regulation of both osteogenesis and osteoclastogenesis and affect bone metabolism. The receptors of the neuronal messengers are expressed in bone cells and their effects depend on catecholamine concentration [28] (Figure 1A).

\section{THE ROLE OF NEUROTROPHINES IN BONE METABOLISM}

Nerve growth factor (NGF) is necessary not only for the development but also for the upkeep of peripheral sensory and post-gangliotic sympathetic nerves [29]. It is present at a specific stage during the differentiation of chondrocytes in the formation of the callus [30]. It has been shown that it evokes rebutter in specific no-classical neural tissues such as the embryonic cartilage rudiments [31]. Another role of NGF is the ability to activate the stimuli for the induction of osteoblastic cells and during the bone differentiation phase may reflect the gradual interplay between bone cells and bone-associated neurons [32].

In general, the production of neurotrophins is placed in the peripheral nervous system by non-neural target cells. It has been proposed that osteoblast-derived neurotrophins may support the maintenance as well as the differentiation of neural cells, but also the multiplication of osteoblasts themselves in bone tissue in vivo, and eventually resulting in bone conformation [33].

\section{THE ROLE OF MUSCLES}

Except from the acute effect of the peripheral nerves on bone growth, the peripheral nervous system may also act on bone metabolism in an indirect way through the muscle system. Firstly, muscle system is responsible for the movements of the body and the limbs. Due to muscles activity, mechanical forces are generated influencing bone metabolism. The observation that compression inhibits bone growth was established since the ancient Roman times [34]. If compression forces always inhibited bone growth, then the growth plates would be unstable and this could lead to major deformities, especially in the growing skeleton [35]. In 1997 Frost [4] proposed with a single graph, that mild compression and tension promote bone growth, whereas these two forces, over a certain limit, have negative effect on bone growth (Figure 1B).

Muscle system is tightly connected with bone growth. Nevertheless, the molecular mechanisms which combine these two different tissues are not well understood. Several experimental and clinical studies have also demonstrated the formation of bone within a traumatized muscle, a phenomenon called myositis ossification [36, 37]. Moreover, osteoblast and osteoclast differentiation, are regulated by leptin which is produced in muscle system, and has a positive effect on bone formation [38-40]. According to this fact, it is assumed that increased muscle mass lead to increased serum leptin levels which in turn promotes bone metabolism [41].

\section{RESULTS OF DENERVATION IN GROWING LIMBS}

After analyzing the effect of peripheral nervous system in bones concerning the molecular level, the macroscopic results of denervation of the bones need to be presented. In 1989 Dysart et al. [42] excised the brachial plexus of Wistar rats and compared the denervated humerus with the ones which were normally innervated. The authors concluded that the denervated humerus were smaller both in length and width compared to the normal ones.

Later, in 1997, Edoff et al. [43] experimented in 7-dayold rat pups and examined their hindfeet, after excision of the sciatic and femoral nerve. The length of the metatarsal bones as well as the total foot length were measured after the denervation and they were compared to the normal ones. Moreover, immunochistochemistry was applied in both groups (denervated and control group). The radiographic examination revealed that the metatarsal bones were significantly shorter in denervated hindfeet. Additionally, in denervated animals, CGRP or SP nerve fibers were not observed in the perichondrium or periosteum of the metatarsal bones on the operated side.

Clinical studies have also demonstrated the effect of peripheral nerve system on bone growth [44, 45]. In 2012 Reading et al. [44] retrospectively reviewed children with neonatal brachial plexus palsy who had underwent joint rebalancing with magnetic resonance imaging (MRI). According to the authors the skewness ratio of the affected humeral head was significantly different from the contralateral limb and was associated with the glenoid version angle and posterior subluxation of the humeral head. The remodeling of the affected humeral head showed significant improvement of the skewness ratio. In 2015 Eismann et al. [46] concluded that patients with brachial plexus palsy present glenogumeral abduction deformities with contractures, which can come up to $65^{\circ}$. One year later, in another study of the same department concerning the osseous outcomes of denervation, the glenohumeral dysplasia was analyzed after neonatal brachial plexus palsy [47]. The authors concluded that the retroversion of the glenoid is a result from growth restriction of the posterior part of the glenoid due to the abnormal innervation.

\section{DISCUSSION AND FUTURE RESEARCH}

Bone growth has been extensively studied. In recent years there is an increasing number of studies trying to analyze the effect of peripheral nervous system in bone metabolism. It seems that peripheral nerves affect the alterations in the structure of the bone, both in an acute and in an indirect way, through the muscle system. A better understanding of the complex neuronal control in the metabolism of the bone is of high importance in situation of traumatized peripheral nerves, such as brachial plexus palsy, in the identification of metabolic and developmental bone disease and in the risk of fracture. A characteristic degenerative disease of bone cartilage is osteoarthritis. Salo et al. [48] supported in their study that an age-related loss of joint innervation may be one of the multiple causes of the degenerative osteoarthritis. 


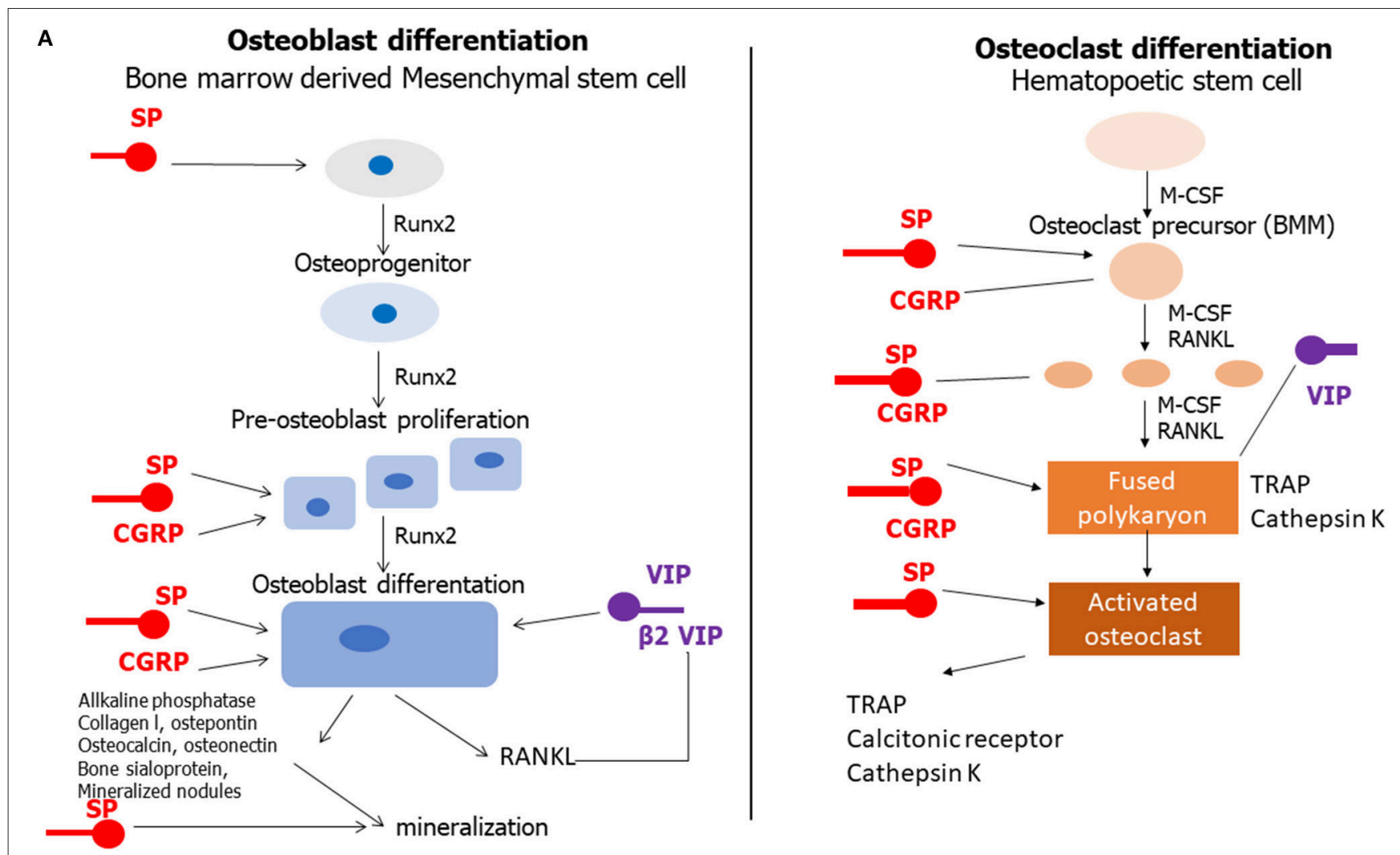

B

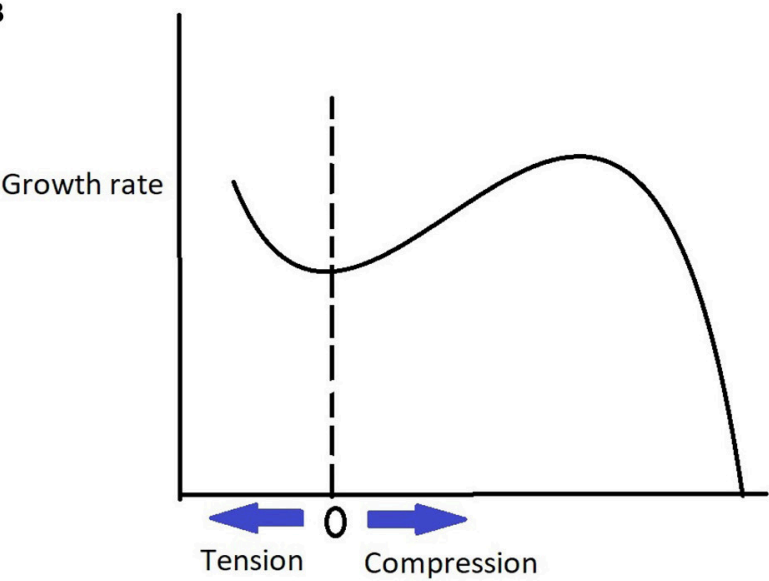

FIGURE 1 | (A) The role of CGRP, VIP and SP in bone metabolism. A line with an arrow at the end shows stimulation, whereas a line without the arrow indicates inhibition. (B) The Frost's graph depicting that compression and tension till a certain level induce bone growth. The horizontal axis depicts load in the growth plate from maximum tension to the left, through 0 to compression in the right. The vertical axis depicts the growth rate.

In this complex association between peripheral nerves and bone homeostasis, CGRP and VIP tend to induce osteoblast activity and inhibit osteoclastogenesis, having anabolic effect on bone remodeling. On the other hand, SP seems to have catabolic effect, which depends on its concentration. It has been also proposed that by blocking certain signals from peripheral nerves to bone, the balance is altered toward bone resorption by inhibiting osteoblast differentiation [28].

Despite the numerous studies showing the role of the peripheral nervous system not only in the physiology but also in the pathophysiology of the bone affecting both the action of osteoblasts and osteoclasts, there is still the need for further research, especially at molecular level. This will allow a 
better understanding of these mechanisms and additionally will provide new directions in understanding skeletal development and skeletal disorders. Moreover, it will create new pathways in the study of osteoporosis, arthropathies, bone tumors and even fracture healing.

\section{CONCLUSION}

The peripheral nervous system is critically involved in bone metabolism. Its role in bone growth is multifactorial, starting from the neuropeptides which regulate the osteoblast and the neurotrophines which in general stimulate the induction of the osteoblastic cells. One of the most striking evidence of a role of the nervous system in the control of bone remodeling is the demonstration that the fat-derived hormone leptin controls bone formation through a hypothalamic relay [49]. From the majority of the studies it is clear that neural tissue is involved in the bone cell functions. The role of muscle system is also of high importance, not only through the mechanical regulation, but also in molecular level. Both experimental and clinical studies conclude that denervated limbs are affected negatively concerning not only the growth but also the orientation of the bone. Nevertheless, more research is needed in order to clarify the exact role of innervation not only as far as it concerns its size and growth, but also its biomechanical properties.

\section{AUTHOR CONTRIBUTIONS}

IGk and DP collected all the data and wrote the biggest part of the mini-review. EP and IK contributed to the writing of the minireview and to the collection of the literature. IGe, MV, and AK reviewed the manuscript and contributed to its final form.

\section{REFERENCES}

1. Van der Eerden B, Karperien M, Wit J. Systemic and local regulation of the growth plate. Endocr Rev. (2003) 24:782-801. doi: 10.1210/er.2002-0033

2. Gkiatas I, Lykissas M, Kostas-Agnantis I, Korompilias A, Batistatou A, Beris A. Factors affecting bone growth. Am J Orthop. (2015) 44:61-7.

3. Turner C. Three rules for bone adaptation to mechanical stimuli. Bone (1998) 23:399-407. doi: 10.1016/S8756-3282(98)00118-5

4. Frost HM. Biomechanical control of knee alignment some insights from a new paradigm. Clin Orthopaed Related Res. (1997) 335:335.

5. Elefteriou F, Campbell P, Ma Y. Control of bone remodeling by the peripheral sympathetic nervous system. Calcif Tissue Int. (2014) 94:140-51. doi: 10.1007/s00223-013-9752-4

6. Cooper RR, Milgram JW, Robinson RA. Morphology of the osteon. An electron microscopic study. J Bone Joint Surg Am. (1966) 48:1239-71. doi: 10.2106/00004623-196648070-00001

7. Cooper RR. Nerves in cortical bone. Science (1968) 160:327-8. doi: 10.1126/science.160.3825.327

8. Hukkanen M, Konttinen YT, Rees RG, Gibson SJ, Santavirta S, Polak JM. Innervation of bone from healthy and arthritic rats by substance $\mathrm{P}$ and calcitonin gene related peptide containing sensory fibers. J Rheumatol. (1992) 19:1252-9.

9. Bjurholm A, Kreicbergs A, Brodin E, Schultzberg M. Substance Pand CGRP-immunoreactive nerves in bone. Peptides (1988) 9:165-71. doi: 10.1016/0196-9781(88)90023-X

10. Hill EL, Elde R. Distribution of CGRP-, VIP-, D beta H-, SP-, and NPYimmunoreactive nerves in the periosteum of the rat. Cell Tissue Res. (1991) 264:469-80. doi: 10.1007/BF00319037

11. Lerner UH, Persson E. Osteotropic effects by the neuropeptides calcitonin gene-related peptide, substance $\mathrm{P}$ and vasoactive intestinal peptide. J Musculoskelet Neuronal Interact. (2008) 8:154-65.

12. Hara-Irie F, Amizuka N, Ozawa H. Immunohistochemical and ultrastructural localization of CGRP-positive nerve fibers at the epiphyseal trabecules facing the growth plate of rat femurs. Bone (1996) 18:29-39. doi: 10.1016/8756-3282(95)00425-4

13. Dietz FR. Effect of denervation on limb growth. J Orthop Res. (1989) 7:292-303. doi: 10.1002/jor.1100070218

14. Garces GL, Santandreu ME. Longitudinal bone growth after sciatic denervation in rats. J Bone Joint Surg Br. (1988) 70:315-8.

15. Konttinen Y, Imai S, Suda A. Neuropeptides and the puzzle of bone remodeling. State of the art. Acta Orthop Scand (1996) 67:632-9. doi: $10.3109 / 17453679608997772$

16. García-Castellano JM, Díaz-Herrera P, Morcuende JA. Is bone a targettissue for the nervous system? New advances on the understanding of their interactions. Iowa Orthop J. (2000) 20:49-58.

17. Gomez C, Burt-Pichat B, Mallein-Gerin F, Merle B, Delmas PD, Skerry TM, et al. Expression of Semaphorin-3A and its receptors in endochondral ossification: potential role in skeletal development and innervation. Dev Dyn. (2005) 234:393-403. doi: 10.1002/dvdy.20512

18. Yoo YM, Kwag JH, Kim KH, Kim CH. Effects of neuropeptides and mechanical loading on bone cell resorption in vitro. Int J Mol Sci. (2014) 15:5874-83. doi: 10.3390/ijms15045874

19. Schwab W, Bilgicyildirim A, Funk R. Microtopography of the autonomic nerves in the rat knee: a fluorescence microscopic study. Anatom Record (1997) 247:109-18. doi: 10.1002/(SICI)1097-0185(199701)247:1<109::AID-AR13>3.0.CO;2-T

20. Zaidi M, Datta HK, Chambers TJ, MacIntyre I. Production and characterisation of immunoreactive calcitonin gene-related peptide (CGRP) from a CGRP receptor-positive cloned osteosarcoma cell line (UMR 106.01). Biochem Biophys Res Commun. (1989) 158:214-9. doi: 10.1016/S0006-291X(89)80200-1

21. Bjurholm A, Kreicbergs A, Dahlberg L, Schultzberg M. The occurrence of neuropeptides at different stages of DBM-induced heterotopic bone formation. Bone Mineral (1990) 10:95-107. doi: 10.1016/0169-6009(90)90085-T

22. Fatatis A, Holtzclaw LA, Avidor R, Brenneman DE, Russell JT. Vasoactive intestinal peptide increases intracellular calcium in astroglia: synergism with alpha-adrenergic receptors. Proc Natl Acad Sci USA. (1994) 91:2036-40. doi: $10.1073 /$ pnas.91.6.2036

23. Hohmann EL, Levine L, Tashjian AH, Jr. Vasoactive intestinal peptide stimulates bone resorption via a cyclic adenosine $3^{\prime}, 5^{\prime}$ monophosphate-dependent mechanism. Endocrinology (1983) 112:1233-9. doi: 10.1210/endo-112-4-1233

24. Imai S, Matsusue Y. Neuronal regulation of bone metabolism and anabolism: calcitonin gene-related peptide-, substance P-, and tyrosine hydroxylasecontaining nerves and the bone. Microsc Res Tech. (2002) 58:61-9. doi: $10.1002 /$ jemt.10119

25. Bjurholm A, Kreicbergs A, Schultzberg M, Lerner UH et al. Neuroendocrine regulation of cyclic AMP formation in osteoblastic cell lines (UMR-106-01, ROS 17/2.8, MC3T3-E1, and Saos-2) and primary bone cells. J Bone Miner Res. (1992) 7:1011-9. doi: 10.1002/jbmr.5650070903

26. Goto T, Yamaza T, Kido MA, Tanaka T. Light-and electron-microscopic study of the distribution of axons containing substance $\mathrm{P}$ and the localization of neurokinin-1 receptor in bone. Cell Tissue Res. (1998) 293:87-93. doi: 10.1007/s004410051100

27. Mori T, Ogata T, Okumura H, Shibata T, Nakamura Y, Kataoka K, Substance P. regulates the function of rabbit cultured osteoclast; increase of intracellular free calcium concentration and enhancement of bone resorption. Biochem Biophys Res Commun. (1999) 262:418-22. doi: 10.1006/bbrc.199 9.1220 
28. Grässel S. The role of peripheral nerve fibers and their neurotransmitters in cartilage and bone physiology and pathophysiology. Arth Res Ther. (2014) 16:485. doi: 10.1186/s13075-014-0485-1

29. Levi-Montalcini R. The nerve growth factor 35 years later. Science (1987) 237:1154-62. doi: 10.1126/science.3306916

30. Grills BL, Schuijers JA. Immunohistochemical localization of nerve growth factor in fractured and unfractured rat bone. Acta Orthop Scand (1998) 69:415-9. doi: 10.3109/17453679808999059

31. Eisenbarth G, Drezner MK, Lebovitz HE. Inhibition of chondromucoprotein synthesis: an extraneuronal effect of nerve growth factor. J Pharmacol Exp Ther. (1975) 192:630-4.

32. Nakanishi T, Takahashi K, Aoki C, Nishikawa K, Hattori T, Taniguchi S. Expression of nerve growth factor family neurotrophins in a mouse osteoblastic cell line. Biochem Biophys Res Commun. (1994) 198:891-7. doi: 10.1006/bbrc.1994.1127

33. Nakanishi T, Ohyama K, Aoki C, Kudo A, Hattori T, Takahashi K, et al. Expression of trkC in a mouse osteoblastic cell line and its response to neurotrophin-3. Biochem Biophys Res Commun. (1994) 203:1268-74. doi: 10.1006/bbrc.1994.2319

34. Arkin AM, Katz JF. The effects of pressure on epiphyseal growth; the mechanism of plasticity of growing bone. J Bone Joint Surg Am. (1956) 38-A:1056-76. doi: 10.2106/00004623-19563805000009

35. Rauch F. Bone growth in length and width: the Yin and Yang of bone stability. J Musculoskelet Neuronal Interact. (2005) 5:194-201.

36. Hamrick MW, McNeil PL, Patterson SL. Role of muscle-derived growth factors in bone formation. J Musculoskelet Neuronal Interact. (2010) 10: 64-70.

37. Hall BK. Cellular differentiation in skeletal tissues. Biol Rev Camb Philos Soc. (1970). 45:455-84. doi: 10.1111/j.1469-185X.1970.tb01174.x

38. Wang J, Liu R, Hawkins M, Barzilai N, Rossetti L. A nutrient-sensing pathway regulated leptin gene expression in muscle and fat. Nature (1998) 393:684. doi: $10.1038 / 31474$

39. Hamrick MW, Ferrari SL. Leptin and the sympathetic connection of fat to bone. Osteoporos Int. (2008) 19:905-12. doi: 10.1007/s00198-0070487-9

40. Takeda S, Elefteriou F, Levasseur R, Liu X, Zhao L, Parker KL. Leptin regulates bone formation via the sympathetic nervous system. Cell (2002) 111:305-17. doi: 10.1016/S0092-8674(02)01049-8
41. Fernandez-Real JM, Vayreda M, Casamitjana R, Gonzalez-Huix F, Ricart W. The fat-free mass compartment influences serum leptin in men. Eur J Endocrinol. (2000) 142:25-9. doi: 10.1530/eje.0.1420025

42. Dysart PS, Harkness EM, Herbison GP. Growth of the humerus after denervation. an experimental study in the rat. J Anat (1989) 167:147-59.

43. Edoff K, Hellman J, Persliden J, Hildebrand C. The developmental skeletal growth in the rat foot is reduced after denervation. Anat Embryol (1997) 195:531-8. doi: 10.1007/s004290050073

44. Reading BD, Laor T, Salisbury SR, Lippert WC, Cornwall R. Quantification of humeral head deformity following neonatal brachial plexus palsy. J Bone Joint Surg Am. (2012) 94:e136. doi: 10.2106/JBJS.K.00540

45. Weekley H, Nikolaou S, Hu L, Eismann E, Wylie C, Cornwall R. The effects of denervation, reinnervation, and muscle imbalance on functional muscle length and elbow flexion contracture following neonatal brachial plexus injury. J Orthop Res. (2012) 30:1335-42. doi: 10.1002/jor.22061

46. Eismann EA, Little KJ, Laor T, Cornwall R. Glenohumeral abduction contracture in children with unresolved neonatal brachial plexus palsy. J Bone Joint Surg Am (2015) 97:112-8. doi: 10.2106/JBJS.N.00203

47. Eismann EA, Laor T, Cornwall R. Three-Dimensional Magnetic Resonance Imaging of Glenohumeral Dysplasia in Neonatal Brachial Plexus Palsy. J Bone Joint Surg Am. (2016) 98:142-51. doi: 10.2106/JBJS.O.00435

48. Salo PT, Seeratten RA, Erwin WM, Bray RC. Evidence for a neuropathic contribution to the development of spontaneous knee osteoarthrosis in a mouse model. Acta Orthop Scand (2002) 73:77-84. doi: $10.1080 / 000164702317281459$

49. Chenu C. Role of innervation in the control of bone remodeling. J Musculoskel Neuron Interact (2004) 4:132.

Conflict of Interest Statement: The authors declare that the research was conducted in the absence of any commercial or financial relationships that could be construed as a potential conflict of interest.

Copyright (c) 2017 Gkiatas, Papadopoulos, Pakos, Kostas-Agnantis, Gelalis, Vekris and Korompilias. This is an open-access article distributed under the terms of the Creative Commons Attribution License (CC BY). The use, distribution or reproduction in other forums is permitted, provided the original author (s) or licensor are credited and that the original publication in this journal is cited, in accordance with accepted academic practice. No use, distribution or reproduction is permitted which does not comply with these terms. 